\title{
Impact of sintering temperature on phase formation, microstructure, crystallinity and ionic conductivity of $\mathrm{Li}_{1.5} \mathrm{Al}_{0.5} \mathrm{Ti}_{1.5}\left(\mathrm{PO}_{4}\right)_{3}$
}

\author{
Bambar Davaasuren ${ }^{1^{\star}}$ and Frank Tietz ${ }^{1,2}$ \\ ${ }^{1}$ Forschungszentrum Jülich GmbH, IEK-1: Materials Synthesis and Processing, D-52425 \\ Jülich, Germany \\ ${ }^{2}$ Helmholtz-Institute Münster, Forschungszentrum Jülich GmbH, D-52425 Jülich, Germany \\ * Corresponding author: $\underline{\text { b.davaasuren@fz-juelich.de }}$
}




\section{Abstract}

A systematic study was carried out to explore the impact of sintering temperature on the densification, phase formation, microstructure, crystallinity, and ionic conductivity of $\mathrm{Li}_{1.5} \mathrm{Al}_{0.5} \mathrm{Ti}_{1.5}\left(\mathrm{PO}_{4}\right)_{3}$ (LATP). There is clear evidence that a) both the total conductivity and bulk conductivity increase with increasing sintering temperature, and b) the phase purity, crystallinity and compositional homogeneity range of LATP are the key factors that influence the bulk ionic conductivity. Furthermore, the influence of a sintering aid $\left(\mathrm{Li}_{2} \mathrm{~B}_{4} \mathrm{O}_{7}\right)$ on the microstructure and ionic conductivity of LATP was probed. The $\mathrm{Li}_{2} \mathrm{~B}_{4} \mathrm{O}_{7}$ improved the microstructural parameters of the LATP electrolyte and thus remarkably reduced the grain boundary resistance of the pristine LATP from $1000 \Omega$ to $550 \Omega$. The sintering aid $\mathrm{Li}_{2} \mathrm{~B}_{4} \mathrm{O}_{7}$ did not influence the stoichiometry or the long-range order of LATP but rather acted as an ion-conducting bridge between the LATP grains facilitating the Li-ion transport.

Keywords: densification, phase formation, microstructure, crystallinity, homogeneity range, ionic conductivity 


\section{Introduction}

High ionic conductivity, and compositional and structural flexibility of phosphates like $\mathrm{Li}_{1+x} \mathrm{M}^{\mathrm{III}}{ }_{x} \mathrm{M}^{\mathrm{IV}} \mathrm{V}_{2-x}\left(\mathrm{PO}_{4}\right)_{3}$ crystallizing with $\mathrm{NaZr}_{2}\left(\mathrm{PO}_{4}\right)_{3}$ (NZP) structure ${ }^{1}$ make these materials attractive as solid electrolytes for ASSBs. Among the Li-containing triphosphates, the Al-substituted lithium titanium phosphate $\mathrm{Li}_{1+x} \mathrm{Al}_{x} \mathrm{Ti}_{2-x}\left(\mathrm{PO}_{4}\right)_{3}$ (LATP) with $0<x<0.5$ has been investigated most due to its chemical stability, high mechanical strength and high ionic conductivity $\left(10^{-4}-10^{-3} \mathrm{~S} \cdot \mathrm{cm}^{-1}\right) \cdot{ }^{2-5}$ LATP crystallizes in the rhombohedral space group $(R \overline{3} c)$, adopting the NZP-type structure. It shows significant thermal expansion anisotropy of the hexagonal unit cell parameters, leading to large stresses and micro-cracks during sintering depending on grain growth. ${ }^{6-10}$ This becomes more pronounced with increasing processing temperature, whereby the micro-cracks lead to a deterioration of ionic conductivity. ${ }^{11-}$ 13 Therefore, it is essential to understand the evolution of microstructural parameters such as porosity, grain size, grain boundary, texture, phase distribution and/or microcrack formation depending on the processing temperature and time. Optimization of above mentioned parameters is the key for the development of high-performance solid electrolytes. In this context, some studies were reported in the literature on LATP powder. For instance, Zhao et al. investigated the effect of calcination temperature on densification and ionic conductivity of LATP, ${ }^{14}$ whereas Kim et al. explored the influence of stoichiometry, hydrothermal reaction time and sintering as well as calcination temperature on the ionic conductivity of hydrothermally synthesized LATP powder. ${ }^{15}$ It was demonstrated that micro-cracking is clearly related to the grain size ${ }^{16}$ and the critical grain size for micro-cracking of Li $i_{1.3} \mathrm{Al}_{0.3} \mathrm{Ti}_{1.3}\left(\mathrm{PO}_{4}\right)_{3}$ was estimated to be $\leq 1.6 \mu \mathrm{m} .{ }^{9}$ However, the impact of sintering temperature on the crystallinity, bulk ionic conductivity as well as the correlation 
between the crystallographic parameters and ionic conductivity of $\mathrm{Li}_{1.5} \mathrm{Al}_{0.5 \mathrm{Ti}} .5\left(\mathrm{PO}_{4}\right)_{3}$ (LATP) has not been reported yet. Furthermore, addition of a small amount of inorganic salt with a low melting point (sintering aid) promotes the coarsening and densification of the ceramic at reduced temperatures. Examples of such salts include $\mathrm{Li}_{3} \mathrm{PO}_{4}, \mathrm{Li}_{3} \mathrm{BO}_{3}, \mathrm{~B}_{2} \mathrm{O}_{3}, \mathrm{LiBO}$, $\mathrm{LiF}$ and $\mathrm{Li}_{2} \mathrm{O}$. These sintering aids improve the microstructural parameters of the ceramic and thereby increase the total ionic conductivity of the solid electrolytes. ${ }^{17-22}$ However, little has been published on sintering aids for the LATP ceramic electrolyte apart from Bai et al.'s communication about the effect of $\mathrm{LiBO}_{2}$ on the microstructure and ionic conductivity of $\mathrm{Li}_{1.3} \mathrm{Al}_{0.3 \mathrm{Ti}} .7\left(\mathrm{PO}_{4}\right)_{3} .{ }^{21}$

Compared with other $\mathrm{Li}^{+}-$ion conducting oxides, e. g. $\mathrm{Li}_{7} \mathrm{La}_{3} \mathrm{Zr}_{2} \mathrm{O}_{12}$ or $\mathrm{Li}_{1+} \times \mathrm{Al}_{x} \mathrm{Ge}_{2}-$ $x\left(\mathrm{PO}_{4}\right)_{3}$, LATP is highly reproducible during powder and component manufacturing and its starting materials are relatively cheap, ${ }^{23,} 24$ making it attractive for large-scale production. A lot of research has already been carried out on producing highly conductive LATP, employing different synthesis routes and tuning the reaction conditions, starting materials as well as processing methods. $5,23,25$ LATP was prepared by melt quenching, co-precipitation, spray drying, sol-gel synthesis, solidstate reaction, hydrothermal synthesis, molten flux and microwave method. ${ }^{13,} 15,23,26$, ${ }^{27}$ An aqueous-based sol-gel method was successfully developed for the preparation of high-grade LATP powders on a kilogram scale. ${ }^{12}$ Furthermore, the synthetic toolset for the synthesis of the triphosphate materials was extended with the solutionassisted solid-state reaction route (SASSR). ${ }^{28,}{ }^{29}$ This method takes into account economic, industrial and environmental aspects: low-cost materials, scalability and utilization of $\mathrm{NO}_{x}$-free precursor materials, respectively.

Here, we report on a systematic investigation of the phase evolution of LATP and on the implication of various parameters affecting the ionic conductivity of LATP to 
understand more about the structure-property relationships. This work explores the impact of the sintering temperature on the densification, phase formation, microstructure and crystallinity as well as total and bulk ionic conductivity of LATP. Furthermore, in comparison to pristine LATP, we present the influence of the sintering aid $\mathrm{Li}_{2} \mathrm{~B}_{4} \mathrm{O}_{7}$ on the microstructure, total and bulk ionic conductivity.

\section{Experimental}

The starting materials lithium hydroxide monohydrate $\mathrm{LiOH} \cdot \mathrm{H}_{2} \mathrm{O}$ (98\% MaTeck $\mathrm{GmbH})$, titanium(IV) isopropoxide $\mathrm{Ti}\left[\mathrm{OCH}\left(\mathrm{CH}_{3}\right)_{2}\right] 4 \quad(97 \%$ Sigma-Aldrich) and orthophosphoric acid $\mathrm{H}_{3} \mathrm{PO}_{4}$ (85\% Merck Chemicals) were used as received. The $\mathrm{Al}^{3+}$ precursor was prepared by dissolving aluminum acetate dibasic $\mathrm{Al}\left[\mathrm{OOCH}_{3}(\mathrm{OH})_{2}\right] \times \mathrm{H}_{2} \mathrm{O}$ in deionized water. The amount of $\mathrm{Al}$ was calculated on the basis of the $\mathrm{Al}_{2} \mathrm{O}_{3}$ formed after the gravimetric analysis of the aluminum acetate aqueous solution. The $\mathrm{Al}_{2} \mathrm{O}_{3}$ content was $\sim 4.3 \mathrm{wt} \%$ based on the average of three samplings.

The LATP powder was prepared by the SASS reaction in aqueous medium, which was previously reported for the preparation of the $\mathrm{Na}_{3} \mathrm{Zr}_{2}\left(\mathrm{SiO}_{4}\right)_{2}\left(\mathrm{PO}_{4}\right) \cdot{ }^{28}$ For the synthesis of $2.1 \mathrm{~mol}(800 \mathrm{~g})$ LATP, $134.99 \mathrm{~g} \mathrm{LiOH} \cdot \mathrm{H}_{2} \mathrm{O}$ was dissolved in deionized water under continuous stirring using a $10 \mathrm{~L}$ beaker. After the complete dissolution of the $\mathrm{LiOH} \cdot \mathrm{H}_{2} \mathrm{O}$, a stoichiometric amount of the Al-acetate solution, namely $1246 \mathrm{~g}$ (based on the content of $4.3 \mathrm{wt} \% \mathrm{Al}_{2} \mathrm{O}_{3}$ ), was slowly added. The resulting homogeneous solution was white, indicating the formation of $\mathrm{Al}(\mathrm{OH})_{3}$ precipitates. To this, $727 \mathrm{~g}$ orthophosphoric acid was gently added. The $\mathrm{Al}(\mathrm{OH})_{3}$ completely dissolved and the reaction mixture turned transparent again. In the final stage, titanium(IV) isopropoxide $(923.81 \mathrm{~g})$ was added while ensuring that the reaction mixture did not 
heat up above $40{ }^{\circ} \mathrm{C}$. The Ti precursor was the last component added to the mixture due to the hydrolysis of Ti-isopropoxide. The reaction mixture containing fine white precipitates was stirred at room temperature for $4 \mathrm{~h}$ and dried in an oven at $80^{\circ} \mathrm{C}$ for $48 \mathrm{~h}$. The dried mass was calcined at $350^{\circ} \mathrm{C}$ for $5 \mathrm{~h}$, with a heating and cooling rate of $3 \mathrm{~K} \cdot \mathrm{min}^{-1}$. After calcination, the powder was milled in absolute ethanol with zirconia balls on a rolling bench for $48 \mathrm{~h}$. The LATP powder was obtained by evaporating the ethanol and sieving with a $30 \mu \mathrm{m}$ sieve.

The particle size distribution was measured by a laser scattering particle analyzer (Horiba LA-950V2) using a suspension prepared by ultrasonication of the LATP powder in ethanol. The elemental composition of the calcined powder was probed by inductively coupled plasma optical emission spectroscopy (ICP-OES), while the sintering behavior of the LATP was determined by dilatometry measurements (DIL 402C, Netzsch) using $8 \mathrm{~mm}$ diameter cylindrical pellets. The calcined powder was uniaxially pressed using a $13 \mathrm{~mm}$ diameter pressing mold by applying $75 \mathrm{MPa}$ pressure and sintered in a muffle furnace in the temperature range between $650{ }^{\circ} \mathrm{C}$ and $1000{ }^{\circ} \mathrm{C}$ with a dwell time of $5 \mathrm{~h}$ and a ramp rate of $3 \mathrm{~K} \cdot \mathrm{min}^{-1}$. The density of the LATP ceramic was measured by Archimedes' method using deionized and degassed water. The phase analyses were carried out using X-ray diffraction (Bruker D4) of the polycrystalline powders and sintered pellets. The HighScore software suite ${ }^{30}$ was employed to index the X-ray diffraction (XRD) patterns. The sintered pellets were embedded in EpoFix Resin (Struers Inc.) and polished with sandpaper using waterfree cutting fluid (Struers Inc.). The fine polishing of the samples were performed using water-free $9 \mu \mathrm{m}, 3 \mu \mathrm{m}$ and $1 \mu \mathrm{m}$ diamond suspensions (Cloeren Technology $\mathrm{GmbH}$ ). After the metallographic preparations, the microstructure of the LATP electrolytes was analyzed by scanning electron microscopy (SEM Zeiss, Merlin) after coating with a thin Pt layer to avoid charging effects. The sintered LATP pellets were 
sputtered with Au on both sides and sealed in Swagelok cells. The ionic conductivity measurements were conducted both in air and Ar atmosphere for comparison. In the latter case, the Au-coated LATP was sealed in Swagelok cells inside an Ar-filled glovebox. The impedance spectra were recorded by a commercial electrochemical system (VMP-300; Bio-Logic SAS) in the low AC frequency range from $7 \mathrm{MHz}$ to 1 $\mathrm{Hz}$ at $25{ }^{\circ} \mathrm{C}$, and in the high frequency range (E4991B Impedance Analyzer, Keysight) from $1 \mathrm{MHz}$ to $3 \mathrm{GHz}$ for all samples sintered at various temperatures. The temperature-dependent impedance measurements between $-30^{\circ} \mathrm{C}$ and $80{ }^{\circ} \mathrm{C}$ were performed only for the samples sintered at $900{ }^{\circ} \mathrm{C}$. The impedance data were fitted by the ZView ${ }^{\circledR}$ software (Scribner Associates Inc.).

\section{Results and discussion}

The chemical analysis with ICP-OES of the calcined LATP powder reveals that the atomic ratio of the constituent elements is in good agreement with the nominal composition (Table 1). The particle size analysis shows a relatively broad monomodal distribution of the particles with $d_{50}=5.73 \mu \mathrm{m}$ (Figure 1a), while the morphology of the calcined powder displays an amorphous mass dominated by porous agglomerates (Figure 1b). A broad hump, corresponding to the amorphous mass, was observed at lower angles of the powder XRD pattern together with $\mathrm{TiO}_{2}$ and $\mathrm{AlPO}_{4}$ as crystalline phases (Figure 2a). The shape and width of the peaks indicate the fine nature of the crystalline phases in the starting material. It should be noted that the LATP phase is not present in the as-calcined powder. 
Table 1. ICP-OES analysis result of the LATP powder calcined at $350{ }^{\circ} \mathrm{C}$ normalized to 3 mol phosphorus $(P)$ per formula unit.

\begin{tabular}{lccc}
\hline Element & Atomic ratio & Nominal composition & Deviation, \% \\
\hline $\mathrm{Li}$ & 1.481 & 1.5 & -1.26 \\
$\mathrm{Al}$ & 0.478 & 0.5 & -4.43 \\
$\mathrm{Ti}$ & 1.530 & 1.5 & 2.01 \\
$\mathrm{P}$ & 3 & 3 & - \\
\hline
\end{tabular}

\subsection{Phase formation, densification and microstructure}

The sintering behavior of the as-calcined powder was examined with dilatometry, where the dimensional change of a pellet is measured with respect to temperature (Figure 1c). For the dilatometry measurements, the same temperature profile was used as for the sintering experiments. The pellet hardly shrinks up to $650{ }^{\circ} \mathrm{C}$, maintaining about $95 \%$ of its original thickness. This is followed by a sharp shrinkage, indicating active densification behavior of the LATP powder. The initial gradual dimensional change is attributed to the decomposition and volatilization of organic residues. According to the dilatometry, a good quality ceramic with high relative density ( $95 \%)$ can be obtained by sintering the material at around $900{ }^{\circ} \mathrm{C}$.
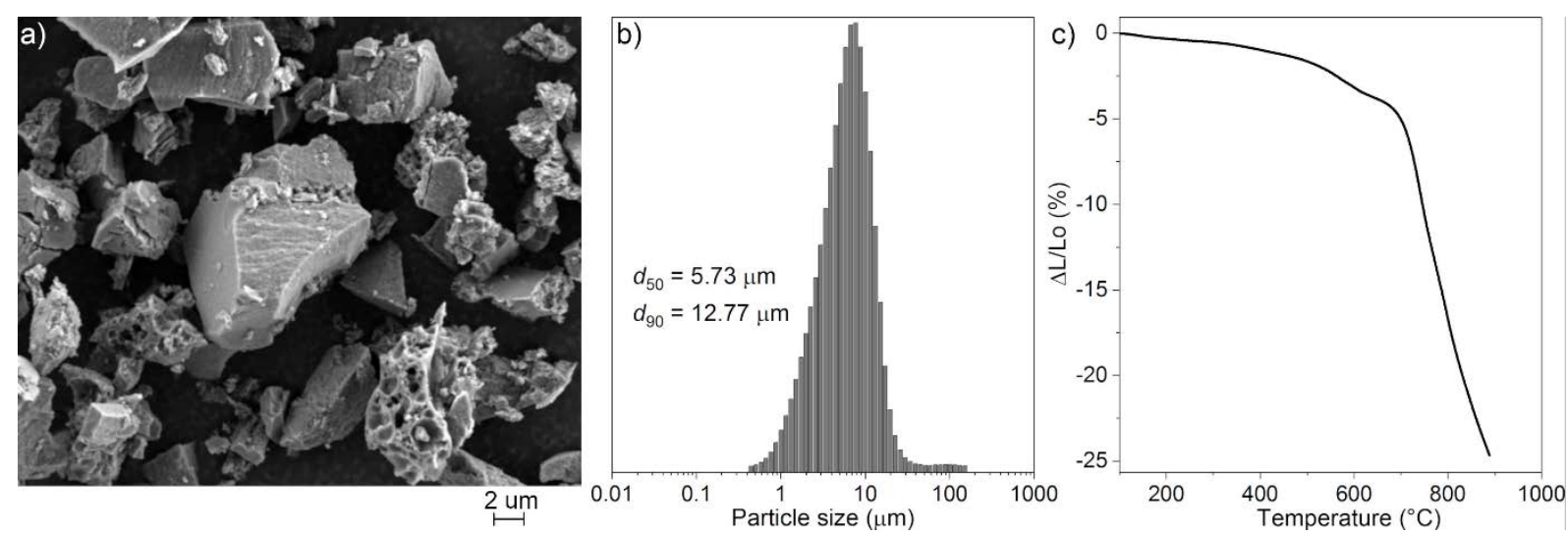

Figure 1. a) Morphology, b) particle size distribution and c) sintering behavior of the LATP powder calcined at $350^{\circ} \mathrm{C}$. 
The uniaxially pressed cylindrical pellets were sintered at different temperatures ranging from $650{ }^{\circ} \mathrm{C}$ to $1000{ }^{\circ} \mathrm{C}$ to explore the phase formation during the sintering process (Figure 2a). The LATP had already been formed as the majority phase in the sample after it was heated at $650{ }^{\circ} \mathrm{C}$. In addition, a small amount of secondary phases such as $\mathrm{Li}_{3} \mathrm{PO}_{4}$ and $\mathrm{AlPO}_{4}$ were present, which gradually vanished with increasing sintering temperature. Due to the anisotropic thermal expansion of LATP, ${ }^{16,31}$ samples heat-treated in the temperature range of $650{ }^{\circ} \mathrm{C}$ to $900{ }^{\circ} \mathrm{C}$ were chosen for further studies to avoid fast grain growth and micro-crack formation.

Figure $2 \mathrm{~b}$ shows the dependence of the relative density of the LATP ceramics on the sintering temperature. As expected, the relative density increases exponentially with increasing sintering temperature. The lowest density of $44 \%$ was obtained at $650{ }^{\circ} \mathrm{C}$, while the highest relative density of $\sim 95 \%$ was achieved at $900{ }^{\circ} \mathrm{C}$, which is in excellent agreement with the dilatometry results. The morphological characteristics of the sintered ceramics, depending on the sintering temperature, were observed exsitu at the microscopic level by the SEM technique (Figure 3).
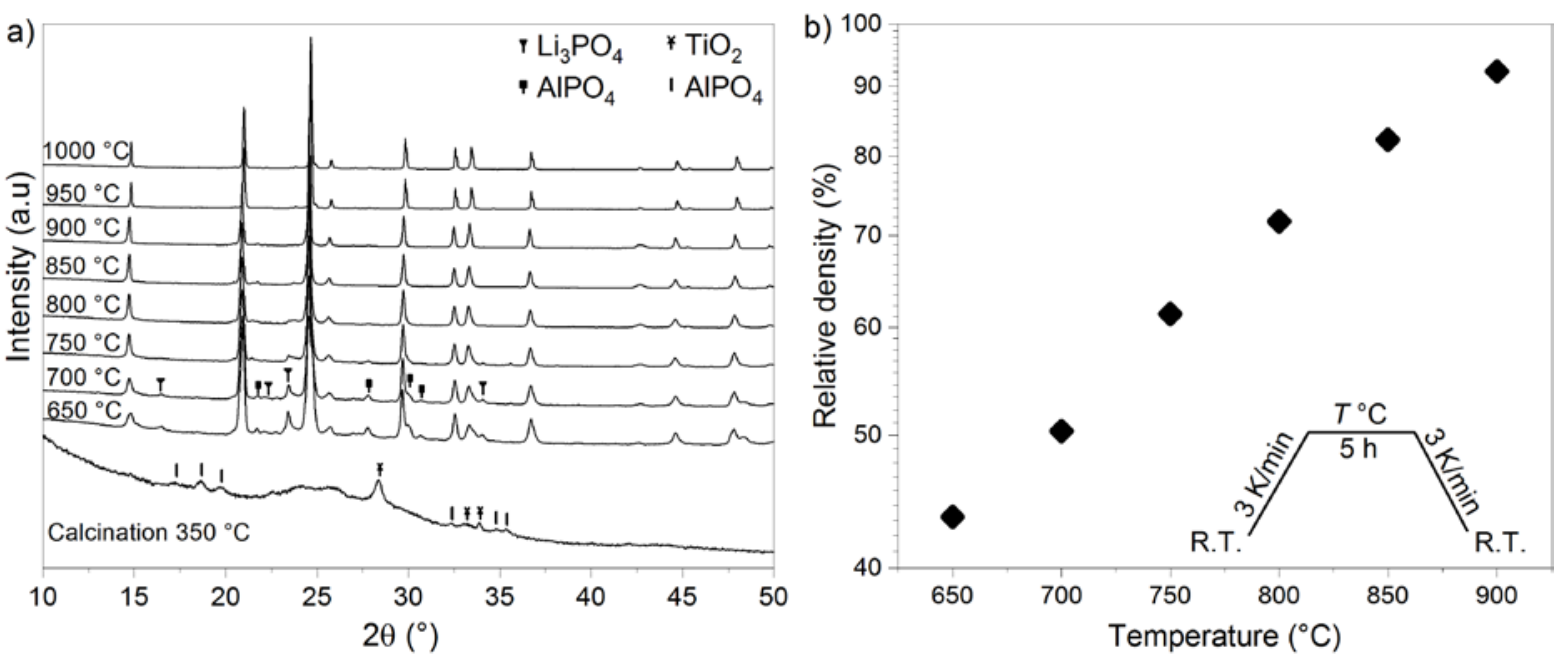

Figure 2. a) Powder XRD patterns and b) relative densities of the LATP pellets sintered at different temperatures. The sintering temperature profile is shown in the inset. The ICDD (International Centre for Diffraction Data) reference codes are: $\mathrm{Li}_{3} \mathrm{PO}_{4}$ (010-074-0358), AlPO 4 (01-070-4689), $\mathrm{TiO}_{2}$ (03-065-6429) and $\mathrm{AlPO}_{4}$ present in the calcined powder (01-076-3498). 
At $650{ }^{\circ} \mathrm{C}$, the fine particles stick together to form porous agglomerates, which look like small islands and are poorly connected to each other. It would appear that at this temperature, the organic residue was utterly burned out, leaving the porous template matrix behind. The skeleton of the porous agglomerates is presumably composed of the LATP. Up to $650{ }^{\circ} \mathrm{C}$, no densification was observed as the density of the sintered pellet was identical to its green density of $\sim 44 \%$. With increasing sintering temperature, the diffusion rate increases facilitating grain growth. As a result, the porosity of the ceramic decreases. Finally, a dense pellet with a welldefined microstructure is formed at $900{ }^{\circ} \mathrm{C}$. The secondary phases of $\mathrm{Li}_{3} \mathrm{PO}_{4}$ and $\mathrm{AlPO}_{4}$ react with each other and are incorporated into the LATP phase with increasing sintering temperature, thereby assisting the densification process. Apart from the rectangular shaped grains of different sizes, grain boundaries, some holes and micro-cracks were observed in the SEM image of the LATP electrolyte sintered at $900{ }^{\circ} \mathrm{C}$. In addition, cleavages of grains from the surface of the sample during the metallographic preparation are clearly visible, which indicates the mechanical instability of the microstructure. The grain size of the particles is not homogeneous, which is typical for samples prepared from agglomerated powder. ${ }^{13}$ 


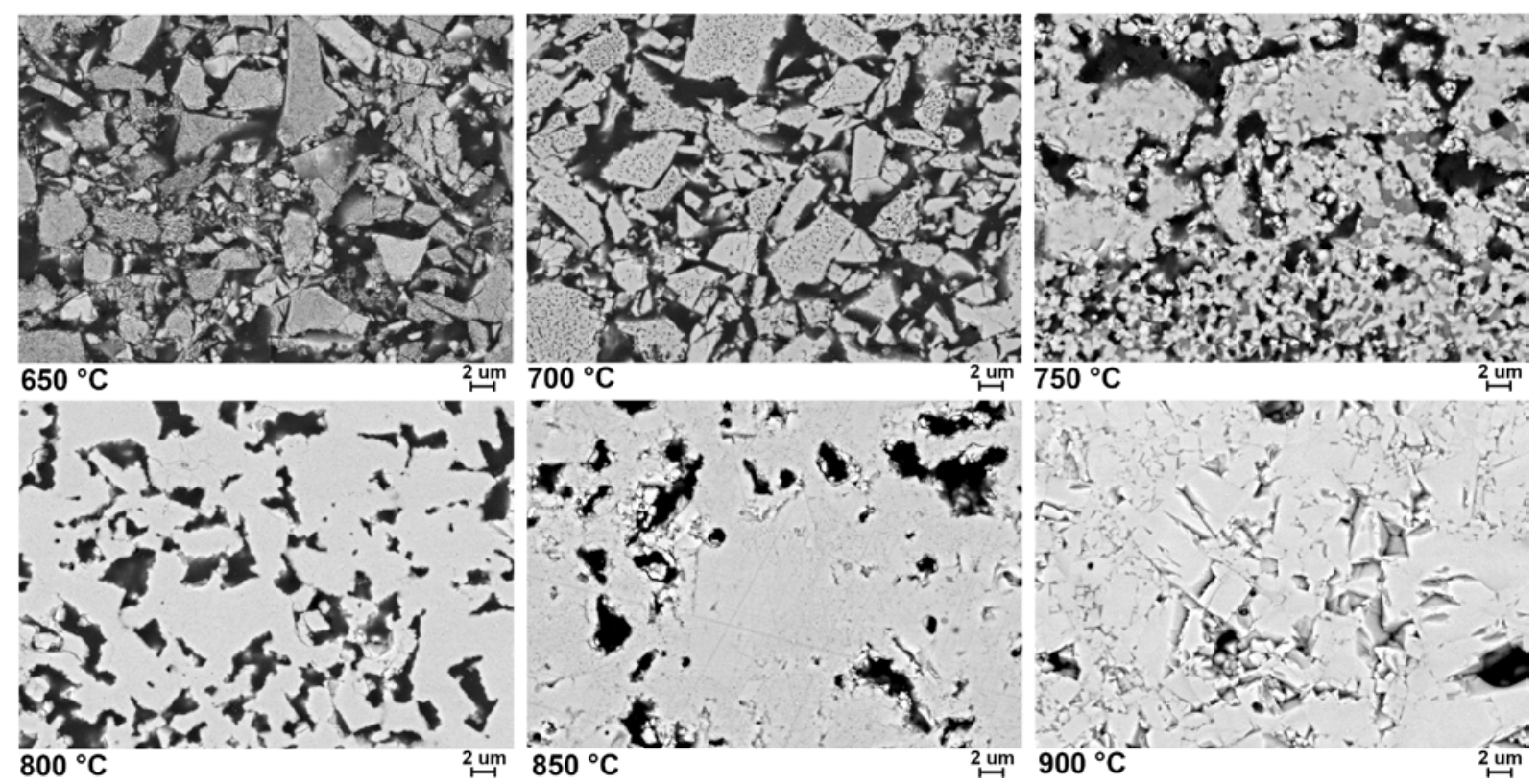

Figure 3. Cross-sectional SEM micrographs of the LATP pellets sintered at different temperatures. The cleavages of grains can be seen on the sample sintered at 900 ${ }^{\circ} \mathrm{C}$.

\subsection{Ionic conductivity}

The total and bulk ionic conductivity of the LATP specimens sintered at $650{ }^{\circ} \mathrm{C}$ to 900 ${ }^{\circ} \mathrm{C}$ was probed by impedance spectroscopy (Figure 4). The impedance diagram of all samples measured in the low frequency range, $1 \mathrm{kHz}-7 \mathrm{MHz}$, displayed only one semicircle or "time constant". The low-frequency impedance data were fitted using a pure resistance $R_{0}$ and two parallel $R-C$ (resistor-capacitor) equivalent circuit elements in series. The constant phase element (CPE) or "imperfect" capacitor was employed to represent the capacitive contribution of the circuit instead of an ideal capacitor. Implementation of the CPE introduces an additional parameter, the exponent $n$, for data fitting. It provides the measure of the non-ideality of the device in tests with values between 0.7 and $1 .{ }^{32}$ The capacitance values calculated using the fitting parameters are in the range of $10^{-10}$ to $10^{-8} \mathrm{~F}$. Therefore, the semicircles observed by low-frequency impedance spectroscopy can be unambiguously 
assigned to the grain boundary resistance $R_{\mathrm{gb}}$ (Figure $4 \mathrm{a}$ ). ${ }^{29,}{ }^{33}$ The second $R-C P E$ circuit is associated with the electrode contribution. As expected, the grain boundary resistance drastically decreases with increasing sintering temperature. The total conductivities of the samples were derived from the resistance values $\left(R_{0}+R_{\mathrm{gb}}\right)$ and plotted against the relative density in Figure 4b. The total ionic conductivity exponentially increases with decreasing porosity and reaches $0.2 \mathrm{~ms} \cdot \mathrm{cm}^{-1}$ at $900{ }^{\circ} \mathrm{C}$. This value is slightly lower than the previously reported values for LATP prepared by the sol-gel method, ${ }^{12}$ and a bit higher than the ionic conductivity of the LATP synthesized by the co-precipitation method. ${ }^{34}$ We attribute this to the morphological
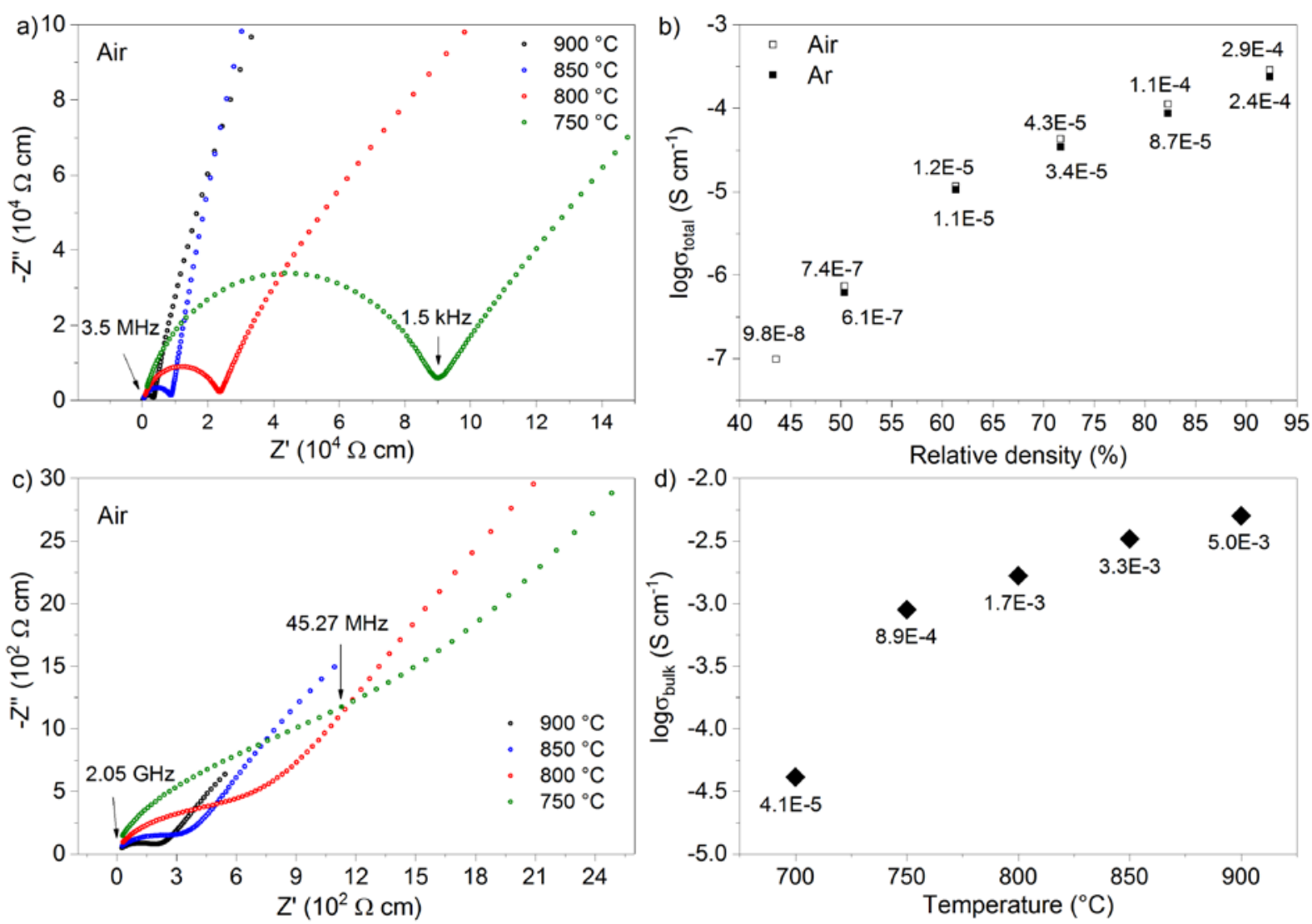

Figure 4. a) Impedance spectra measured in the low frequency range, b) total ionic conductivity at various relative densities, c) impedance spectra measured in the high frequency range and d) bulk ionic conductivity as a function of sintering temperature. The impedance values are normalized to the size of the pellets. 
characteristics of the primary particles and subsequently to the microstructural parameters of the ceramic, rather than to the charge carrier concentration $\left(\mathrm{Li}^{+}\right)$. The dependency of the ionic conductivity on the sintering temperature fits well with the general picture observed by cross-sectional SEM.

The ionic conductivity was measured both in air and in argon (Ar) atmosphere for comparison. Interestingly, the ionic conductivities measured in air are higher than those measured in Ar atmosphere at all sintering temperatures. Presumably, the adsorbed humidity in air serves as a contacting/conducting bridge between the grains and therefore reduces the grain boundary resistance. This was also the assumption made by Dashjav et al., who showed that moisture initially increases the ionic conductivity of the LATP, but that the extended contact of LATP with water results in the decomposition of the microstructure and therefore deterioration of the ionic conductivity. ${ }^{35}$

Since the low-frequency impedance spectra could not detect the bulk resistance of the LATP electrolyte, high-frequency impedance measurements from $1 \mathrm{MHz}$ to 3 $\mathrm{GHz}$ were also carried out (Figure 4c). These impedance spectra also show only one semicircle in the high frequency range. The data were fitted using two parallel $R-C P E$ circuits in series. The capacitance associated with the high-frequency arc was determined as $10^{-12} \mathrm{~F}$. This was identified as a bulk property with a large volume fraction. ${ }^{33}$ Thus, the $R-C P E$ circuits correspond to the bulk $\left(R_{\mathrm{b}}-C P E_{\mathrm{b}}\right)$ and grain boundary $\left(R_{\mathrm{gb}}-C P E_{\mathrm{gb}}\right)$ contributions. As previously mentioned, the bulk ionic conductivity is an intrinsic property of a material with a given composition and crystal structure. Therefore, the bulk conductivity is not expected to be affected by the sintering temperature. However, in analogy to the total conductivity, the bulk 
conductivity asymptotically increases by two orders of magnitude with increasing sintering temperature (Figure $4 d$ ). This must be related to crystallographic properties like the crystallinity and compositional homogeneity of the LATP electrolytes sintered at various temperatures. Indeed, the long-range order of the material is a prerequisite for successful ion conduction in extended solids. The crystallinity or the long-range order of the material can be estimated from the shape of the XRD reflections expressed by the full width at half maximum (FWHM) of the diffraction peaks. The (102) peak at $2 \theta=14.8^{\circ}$ was selected for FWHM analysis due to the overlap of other LATP peaks with the reflections of the secondary phases. For the profile fitting, a Pseudo-Voigt function with half Gaussian and half Lorentzian contributions was used. Figure $5 \mathrm{a}$ shows the correlation between FWHM and sintering temperature, where the comparison of the (102) peak at various sintering temperatures is shown in the inset. The FWHM is inversely proportional to the crystallinity. At $650{ }^{\circ} \mathrm{C}$, the $(102)$ peak displays a broad hump-like profile with a relatively large FWHM of $0.32^{\circ}$, indicating a poor crystalline nature of the LATP. The crystallinity drastically increases up to $800{ }^{\circ} \mathrm{C}$ and then becomes slowly saturated. As expected, the highest crystallinity was achieved at $900{ }^{\circ} \mathrm{C}$, where LATP exhibits a well-defined sharp peak with the lowest FHWM of $0.12^{\circ}$. In Figure $5 \mathrm{~b}$, the bulk ionic conductivity is plotted as a function of FWHM. The bulk ionic conductivity appears to be extremely sensitive to the crystallinity of the LATP electrolyte. The LATP electrolyte sintered at $900{ }^{\circ} \mathrm{C}$ possessed the highest bulk conductivity of $5 \cdot 10^{-3} \mathrm{~S} \cdot \mathrm{cm}^{-1}$, which agrees well with the values reported in the literature for the same composition, $3.4 \cdot 10^{-3}-5.8 \cdot 10^{-3} \mathrm{~S} \cdot \mathrm{cm}^{-1}{ }^{8}$, 35-37 $\mathrm{Ma}$ et al. reported that the bulk ionic conductivity of $\mathrm{Li}_{1.3} \mathrm{Al}_{0.3} \mathrm{Ti}_{1.7}\left(\mathrm{PO}_{4}\right)_{3}$ almost remains unchanged, i.e. varying only between $1.88 \cdot 10^{-3}$ and $2.48 \cdot 10^{-3} \mathrm{~S} \cdot \mathrm{cm}^{-1}$ after heat treatments in the temperature range of $700{ }^{\circ} \mathrm{C}-850{ }^{\circ} \mathrm{C} .{ }^{31}$ These results deviate from our observations, especially at lower temperatures, due to the difference in 
calcination temperature, sintering time and stoichiometry of the LATP powder (700 ${ }^{\circ} \mathrm{C}, 12 \mathrm{~h}$ and $x=0.3$ in ref. 37 , respectively).
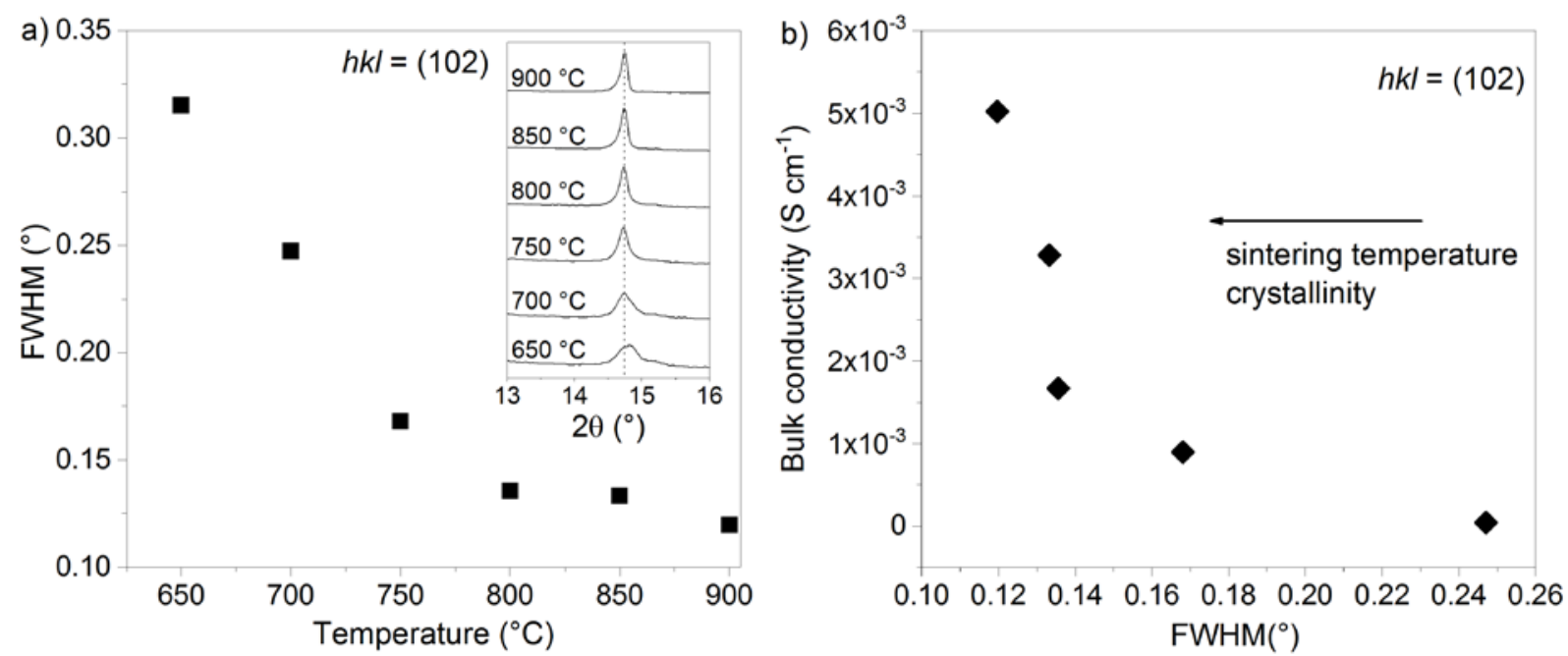

Figure 5. a) FWHM of the (102) peak as a function of the sintering temperature and b) the bulk ionic conductivity shown as a function of FWHM (crystallinity).

The average crystallite size, calculated using the Debye-Scherrer equation (see Figure 6a) with the Scherrer constant $K=0.9$ and the $X$-ray wavelength $\lambda=0.15418$ $\mathrm{nm}$, becomes larger with increasing sintering temperature (Figure 6a). This regularity is related to the increase in the diffusion rate with temperature. As a result, the fine particles form larger grains/crystallites, which have a higher degree of long-range ordering.

In addition, the charge carrier concentration or the number of $\mathrm{Li}^{+}$ions within LATP will directly affect the bulk conductivity. Since the samples sintered below $900{ }^{\circ} \mathrm{C}$ have larger FWHM values, this may also be related to a stoichiometric variation within the LATP phase and to a sub-stoichiometry or low substitution degree of $\mathrm{Ti}^{4+}$ by $\mathrm{Al}^{3+}$ ions, with $x<0.5$ in $\mathrm{Li}_{1+x} \mathrm{Al}_{x} \mathrm{Ti}_{2-x}\left(\mathrm{PO}_{4}\right)_{3}$, due to the incompleteness of the solidstate reaction and presence of the secondary phases. The variation in stoichiometry should be identified by the unit cell parameters, which correlate with $x$. Therefore, the 
powder XRD patterns in Figure 2a were indexed to determine the respective unit cell volumes. Systematic crystal structure studies on the LATP single crystals with different stoichiometric compositions have already been published ${ }^{7}$. A reference plot was constructed using the reported values of the unit cell volumes against the substitution degree of $\mathrm{Ti}^{4+}$ with $\mathrm{Al}^{3+}$ ions within the crystal structure of LATP (Figure $6 b)$. Using this reference plot, the average stoichiometry of the samples was estimated by putting the unit cell volumes on the curve and finding the respective $x$ values. The highest possible substitution degree of $x=0.5$ was obtained at $900{ }^{\circ} \mathrm{C}$, and drops with decreasing sintering temperature, reaching $x=0.42$ at $750{ }^{\circ} \mathrm{C}$. This experimental evidence indicates that at lower sintering temperatures, the samples have a small compositional homogeneity range, which may result in lower bulk ionic conductivity. As the powder XRD patterns of the samples sintered at $650{ }^{\circ} \mathrm{C}$ and 700 ${ }^{\circ} \mathrm{C}$ could not be reliably indexed, the unit cell volumes of these samples are not displayed in the graph. However, the other four data points represent the general tendency.
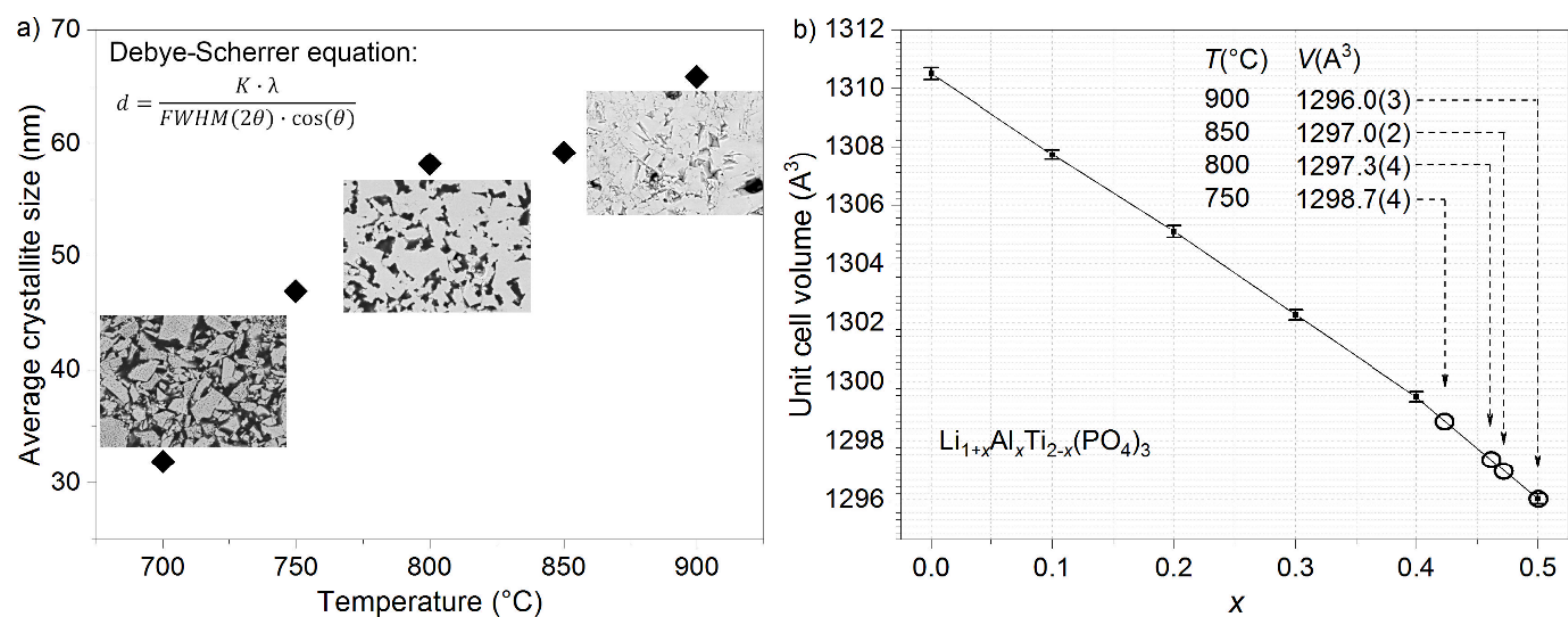

Figure 6. a) Dependence of the average crystallite size on the sintering temperature, b) correlation between unit cell volume and the substitution degree $x$ in LATP. 


\subsection{Impact of sintering aids on the microstructure and ionic conductivity}

As previously mentioned, it is well known that the sintering additives have a positive impact on the densification, microstructure and ionic transport properties of LATP. ${ }^{17}$, ${ }^{21}$ Therefore, the effect of various sintering aids such as $\mathrm{Li}_{3} \mathrm{PO}_{4}$ (m.p. $837^{\circ} \mathrm{C}$ ), $\mathrm{LiBO}_{2}$ (m.p. $845^{\circ} \mathrm{C}$ ), LiF (m.p. $845^{\circ} \mathrm{C}$ ) and $\mathrm{Li}_{2} \mathrm{~B}_{4} \mathrm{O}_{7}$ (m.p. $880^{\circ} \mathrm{C}$ ) on LATP were studied. The sintering aids were mixed with the calcined LATP powder in varying weight ratios (sintering aid: $0.5 \mathrm{wt} \%, 1 \mathrm{wt} \%$ and $2 \mathrm{wt} \%$ ) and sintered at $900{ }^{\circ} \mathrm{C}$. Overall, the sintering aids did not drastically increase the densification of the pellets, only by about $1 \%$. The $\mathrm{Li}_{3} \mathrm{PO}_{4}, \mathrm{LiBO}_{2}$, $\mathrm{LiF}$ as well as $1 \mathrm{wt} \%$ and $2 \mathrm{wt} \% \mathrm{Li}_{2} \mathrm{~B}_{4} \mathrm{O}_{7}$ increased the fraction and crystallinity of the secondary phases, $\mathrm{Li}_{3} \mathrm{PO}_{4}$ and $\mathrm{AlPO}{ }_{4}$, after sintering. In contrast, the addition of 0.5 wt $\% \mathrm{Li}_{2} \mathrm{~B}_{4} \mathrm{O}_{7}$ improved the purity of the sample. Therefore, a new series of sintered pellets were prepared for sintering experiments in the same temperature range of $650{ }^{\circ} \mathrm{C}$ to $900{ }^{\circ} \mathrm{C}$ from the LATP powder calcined at $350{ }^{\circ} \mathrm{C}$ mixed with $0.5 \mathrm{wt} \% \mathrm{Li}_{2} \mathrm{~B}_{4} \mathrm{O}_{7}$. Figure 7 shows the microstructure of the pristine LATP in comparison with $\mathrm{Li}_{2} \mathrm{~B}_{4} \mathrm{O}_{7}$-treated LATP, both sintered at $900{ }^{\circ} \mathrm{C}$. The SEM micrographs show that the $\mathrm{Li}_{2} \mathrm{~B}_{4} \mathrm{O}_{7}$ improved the contact between the grains, strengthened the grain boundaries and stabilized the microstructure of the LATP electrolyte. Compared to the pristine LATP, there are no cleavages of grains visible on the $\mathrm{Li}_{2} \mathrm{~B}_{4} \mathrm{O}_{7}$-treated sample after metallographic preparation.

The low-frequency impedance spectrum of the $0.5 \mathrm{wt} \% \mathrm{Li}_{2} \mathrm{~B}_{4} \mathrm{O}_{7}$-treated LATP is shown in Figure $8 \mathrm{a}$ in comparison with the pristine LATP, both sintered at $900{ }^{\circ} \mathrm{C}$. Similar to the pristine sample, the low-frequency impedance spectrum of $0.5 \mathrm{wt} \%$ $\mathrm{Li}_{2} \mathrm{~B}_{4} \mathrm{O}_{7}$-treated LATP exhibits only one semicircle, which belongs to the grain boundary impedance. The grain boundary resistance of the pristine LATP was remarkably reduced from about $3500 \Omega \cdot \mathrm{cm}$ to around $1500 \Omega \cdot \mathrm{cm}$ with the addition of 
$\mathrm{Li}_{2} \mathrm{~B}_{4} \mathrm{O}_{7}$. However, the bulk resistance was similar in both cases, indicating the same level of crystallinity and compositional stoichiometry of the pristine and the $\mathrm{Li}_{2} \mathrm{~B}_{4} \mathrm{O}_{7}-$ containing LATP ceramics (Figure 8a inset).
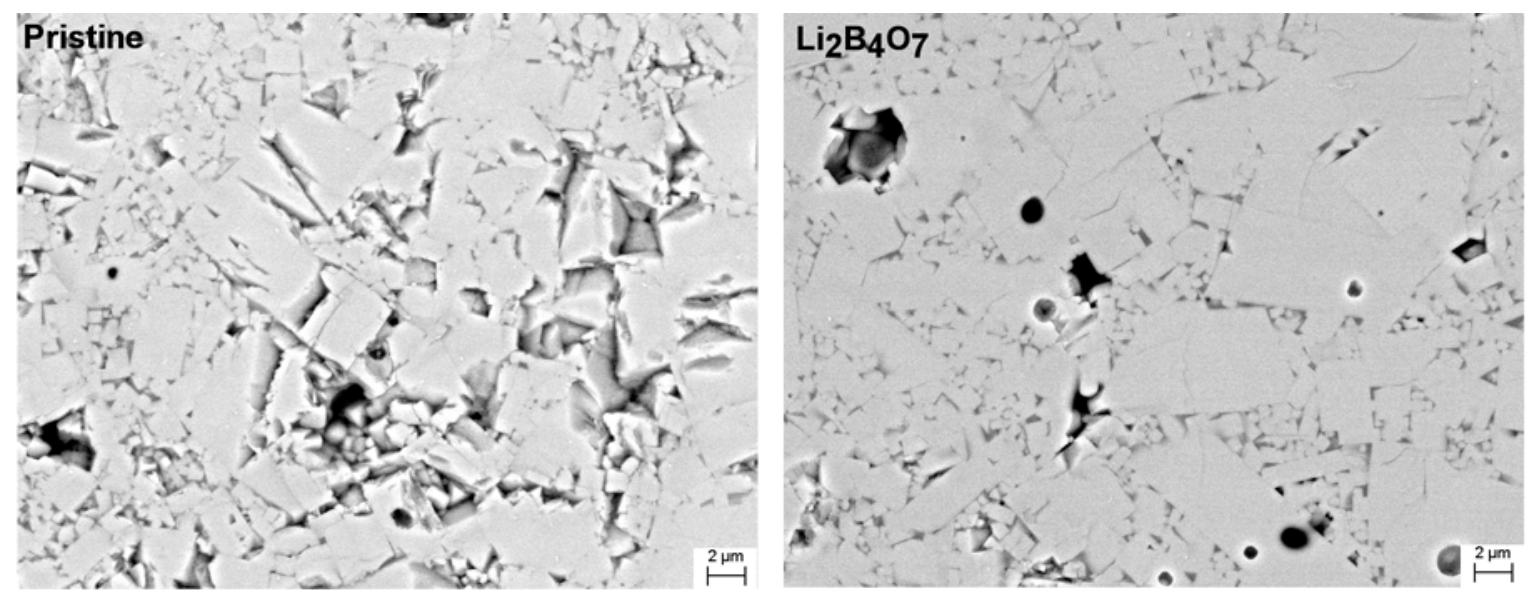

Figure 7. The microstructure of the pristine LATP electrolyte in comparison with 0.5 $w t \% \mathrm{Li}_{2} \mathrm{~B}_{4} \mathrm{O}_{7}$-treated LATP ceramic. Both samples were sintered at $900{ }^{\circ} \mathrm{C}$ using the same sintering profile.

Therefore, the $\mathrm{Li}_{2} \mathrm{~B}_{4} \mathrm{O}_{7}$ does not have an impact on the stoichiometry or the longrange order of the LATP, but rather acts as an ion-conducting bridge between the LATP grains. The total ionic conductivity of the $\mathrm{Li}_{2} \mathrm{~B}_{4} \mathrm{O}_{7}$-treated LATP ceramic was more than twice that of pristine LATP sintered at $900{ }^{\circ} \mathrm{C}$ (Figure 8b). The conductivity measured in air was again slightly higher than in Ar atmosphere. In the whole temperature range, the total ionic conductivity of the $\mathrm{Li}_{2} \mathrm{~B}_{4} \mathrm{O}_{7}$-treated samples was higher than for the corresponding pristine LATP, which confirms the hypothesis that the $\mathrm{Li}_{2} \mathrm{~B}_{4} \mathrm{O}_{7}$ acts as a modifier of the grain boundaries (Figure 8c). Temperaturedependent impedance studies were carried out to determine the activation energy $\left(E_{a}\right)$ of the ion conduction using the Arrhenius expression: $T=A \cdot \exp \left(-\frac{E_{a}}{k T}\right)$, where $\sigma$ is the ionic conductivity of the sample, $A$ is the pre-exponential factor, $k$ is the Boltzmann constant and $T$ is the absolute temperature. Figure $8 \mathrm{~d}$ shows the 
Arrhenius plot of the pristine LATP electrolyte and 0.5 wt $\% \mathrm{Li}_{2} \mathrm{~B}_{4} \mathrm{O}_{7}$-treated LATP electrolyte measured between $-30{ }^{\circ} \mathrm{C}$ and $80{ }^{\circ} \mathrm{C}$. The activation energy, $E_{a}$, was obtained from the linear fit of the experimental data. The $E_{a}$ value for the pristine LATP was $0.41 \mathrm{eV}$, which is comparable with the values reported in the literature. ${ }^{12}$ In contrast, the Arrhenius plot of the $\mathrm{Li}_{2} \mathrm{~B}_{4} \mathrm{O}_{7}$-treated LATP electrolyte showed a shallower slope compared to the pristine sample, indicating a lower activation energy $\left(E_{a}=0.37 \mathrm{eV}\right)$

The obtained total conductivities of the pristine and $\mathrm{Li}_{2} \mathrm{~B}_{4} \mathrm{O}_{7}$-containing samples were compared with the density-dependent conductivities in previous studies. The compiled data are shown in Figure 9. In the overall view, irrespective of the considered substitution level, the ionic conductivity of LATP ceramics shows a logarithmic dependence on the relative density and appears to end at 1.0-1.3 $\mathrm{mS} \cdot \mathrm{cm}^{-1}$ for fully densified samples. There are only two reports which deviate from this general trend. In the case of Ma et al. ${ }^{36}$, this terminal value was already reached at a density of about $90 \%$. Interestingly, in a different publication ${ }^{14}$, the same group presented data that are in full agreement with the other studies. 

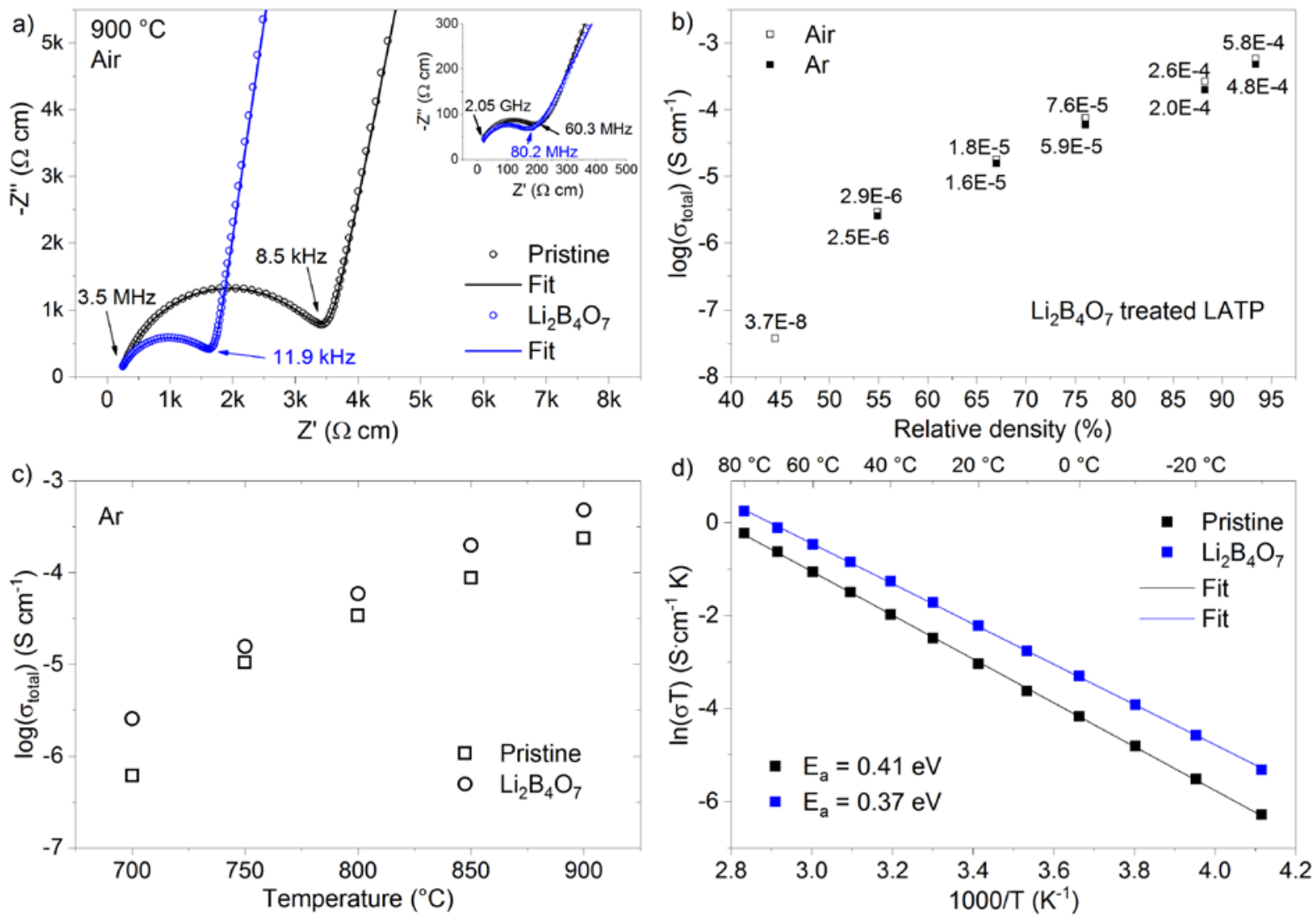

Figure 8. a) Impedance diagram of the pristine LATP compared with $0.5 \mathrm{wt} \%$ $\mathrm{Li}_{2} \mathrm{~B}_{4} \mathrm{O}_{7}$-treated LATP. The high-frequency measurement is shown in the inset. The impedance data are normalized to the size of the pellets. $b$ ) Total ionic conductivity of $\mathrm{Li}_{2} \mathrm{~B}_{4} \mathrm{O}_{7}$-treated LATP sintered at various temperatures shown as a function of relative density. c) Comparison of the total ionic conductivity of pristine LATP with $\mathrm{Li}_{2} \mathrm{~B}_{4} \mathrm{O}_{7}$-treated LATP at all sintering temperatures. d) Temperature-dependent ionic conductivity of the pristine LATP and $\mathrm{Li}_{2} \mathrm{~B}_{4} \mathrm{O}_{7}$-treated LATP electrolyte.

In the other case, Bucharsky et al. ${ }^{38}$ reported total conductivities up to $7 \mathrm{mS} \cdot \mathrm{cm}^{-1}$ (figure 6 in ref. 45). This result even surpasses the bulk conductivity values of LATP (see above) and we would go so far as to say that it appears unrealistic. In fact, using the information given for sample dimensions and the impedance data in ref. 45 , we calculated a value of $0.64 \mathrm{mS} \cdot \mathrm{cm}^{-1}$ for the sample with the highest conductivity, which justifies a division of the presented data by a factor of ten, and would then also be in very good agreement with the other datasets. 


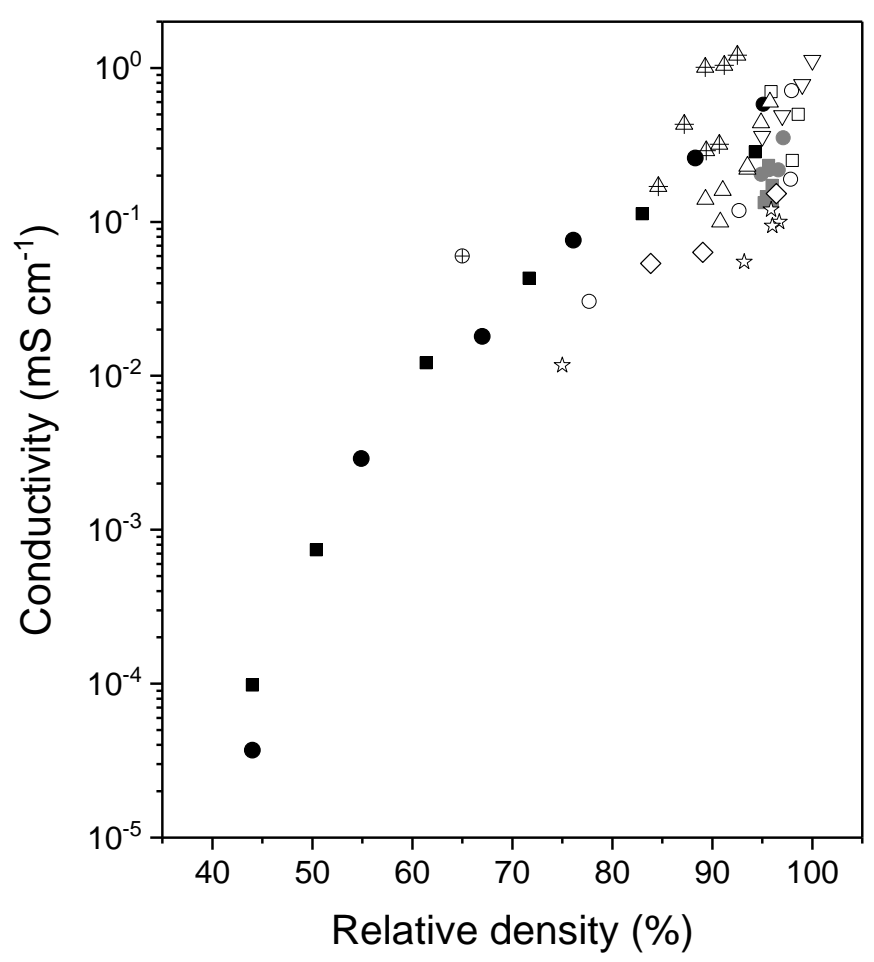

Figure 9. Total conductivity of LATP electrolyte with $0.3<x<0.5$ as a funtion of relative density. The filled black symbols show the results of this work ( $\boldsymbol{\square}$ : pristine $\mathrm{Li}_{1.5} \mathrm{Al}_{0.5} \mathrm{Ti}_{1.5}\left(\mathrm{PO}_{4}\right)_{3}$, - : $\left.\mathrm{Li}_{1.5} \mathrm{Al}_{0.5 \mathrm{Ti}} \mathrm{Ti}_{1.5}\left(\mathrm{PO}_{4}\right)_{3}+0.5 \mathrm{wt} \% \mathrm{Li}_{2} \mathrm{~B}_{4} \mathrm{O}_{7}\right)$; the filled gray symbols refer to data taken from ref. 28 ( $\square$ : pristine $\mathrm{Li}_{1.3 \mathrm{Al}} \mathrm{Al}_{0.3 \mathrm{Ti}} \mathrm{Ti}_{1.7}\left(\mathrm{PO}_{4}\right)_{3}, \quad \mathrm{O}$ : $\left.\mathrm{Li}_{1.3} \mathrm{Al}_{0.3} \mathrm{Ti}_{1.7}\left(\mathrm{PO}_{4}\right)_{3}+0.5-2 \mathrm{wt} \% \mathrm{LiBO}_{2}\right) ; \mathrm{Li}_{1+x} \mathrm{Al}_{x} \mathrm{Ti}_{2-x}\left(\mathrm{PO}_{4}\right)_{3}$ with $x=0.3,0.4,0.5$ $(\square)^{39} ; \mathrm{Li}_{1.4} \mathrm{Al}_{0.4 \mathrm{Ti}} \mathrm{Ti}_{1.6}\left(\mathrm{PO}_{4}\right)_{3}(\diamond)^{40}$; $\mathrm{Li}_{1.3} \mathrm{Al}_{0.3} \mathrm{Ti}_{1.7}\left(\mathrm{PO}_{4}\right)_{3}(\nabla)^{41}$ and $(\bigcirc)^{38}$; values were divided by factor of ten (see text); $(\triangle)^{42},(\triangle)^{31},(\oplus)^{43}$ and $(\text { 江 })^{10}$.

Several publications have reported decreasing conductivity and density with increasing sintering temperature, indicating an excessive energy impact and crack formation. Despite the fact that the increasing porosity is due to crack formation, such data points were also included in Figure 9 and do not violate the general trend. The samples containing sintering aids follow the same trend, as can be clearly seen from the filled black and gray symbols in Figure 9. The scattering of the data mainly arises from different powder qualities and their sintering properties, which may result in different microstructural features like particle size distribution, amount of secondary phases, grain boundary thicknesses etc. even though the porosity might be constant. 


\section{Conclusions}

LATP with good powder quality was successfully synthesized by a newly developed SASS route using $\mathrm{NO}_{x}$-free precursors, which can be easily scaled up. The relative density, phase purity, microstructure formation and grain boundary resistance of the LATP electrolyte are controlled by the solid-state reaction of the starting materials at lower temperatures and by the diffusion processes in the higher temperature range. It turned out that the total conductivity and bulk ionic conductivity depend on the sintering temperature. The crystallinity or the long-range order determines the bulk ionic conductivity of the LATP electrolyte, facilitating fast and smooth ion transport through the crystal lattice. In addition, it was observed that the LATP electrolytes had a small compositional homogeneity range at lower sintering temperatures. The charge carrier concentration $\left(\mathrm{Li}^{+}\right)$was reduced and consequently ionic conductivity decreased. Therefore, finally, the crystallinity, phase purity and compositional homogeneity range are the main factors governing the bulk transport property. While the dependence of total conductivity on density has been investigated many times, to our knowledge it is the first time proven that also the bulk conductivity follows a similar trend. In the latter case, however, the increase of temperature during heat treatment changes the crystalline properties, which are simultaneously varying with the macroscopic microstructural properties.

In addition, the influence of different sintering aids were tested to improve the ionic conductivity of the LATP electrolyte. The $0.5 \mathrm{wt} \% \mathrm{Li}_{2} \mathrm{~B}_{4} \mathrm{O}_{7}$ showed the most promising results of the four selected sintering aids. $\mathrm{Li}_{2} \mathrm{~B}_{4} \mathrm{O}_{7}$ enhances the contact between the grains, strengthens the grain boundaries and therefore stabilizes the microstructure of the LATP electrolyte. As a result, the grain boundary resistance was remarkably 
reduced and the total ionic conductivity was doubled. The $\mathrm{Li}_{2} \mathrm{~B}_{4} \mathrm{O}_{7}$ sintering aid acts as an ion-conducting bridge between the LATP grains and does not have an impact on the bulk conductivity of the LATP electrolyte.

\section{Acknowledgement}

We thank Dr. D. Grüner (FZJ, IEK-2) for the SEM investigations and Dr. Q. Ma for the high-frequency impedance measurements, M. Andreas and V. Bader for technical assistance, and A. Hilgers and S. Pristat for PSD and dilatometry measurements, respectively. Thanks are also given to our colleagues at the Central Institute of Engineering, Electronics and Analytics (ZEA-3) for the ICP-OES analysis.

The results of this work are part of the project "BCT - Battery Cell Technology" funded by the German Federal Ministry of Education and Research (BMBF) under support code 03XP0109E. The authors take responsibility for the content of this publication.

\section{Conflict of Interest}

There are no conflicts of interests to declare.

\section{References}

1. L. O. Hagman and P. Kierkegaard, Acta Chem. Scand., 1968, 22, 1822-1832.

2. H. Aono, E. Sugimoto, Y. Sadaoka, N. Imanaka and G. y. Adachi, J. Electrochem. Soc., 1989, 136, 590-591.

3. H. Aono, E. Sugimoto, Y. Sadaoka, N. Imanaka and G. y. Adachi, J. Electrochem. Soc., 1990, 137, 1023-1027.

4. Y. Wang, W. D. Richards, S. P. Ong, L. J. Miara, J. C. Kim, Y. Mo and G. Ceder, Nat. Mater., 2015, 14, 1026.

5. F. Zheng, M. Kotobuki, S. Song, M. O. Lai and L. Lu, J. Power Sources, 2018, 389, 198-213.

6. K. Arbi, M. Hoelzel, A. Kuhn, F. García-Alvarado and J. Sanz, Inorg. Chem., 2013, 52, 9290.

7. G. J. Redhammer, D. Rettenwander, S. Pristat, E. Dashjav, C. M. N. Kumar, D. Topa and F. Tietz, Solid State Sci., 2016, 60, 99-107.

8. D. Rettenwander, A. Welzl, S. Pristat, F. Tietz, S. Taibl, G. J. Redhammer and J. Fleig, J. Mater. Chem. A, 2016, 4, 1506-1513.

9. S. D. Jackman and R. A. Cutler, J. Power Sources, 2012, 218, 65-72.

10. K. Waetzig, A. Rost, U. Langklotz, B. Matthey and J. Schilm, J. Eur. Ceram. Soc., 2016, 36, 1995-2001. 
11. C. Vinod Chandran, S. Pristat, E. Witt, F. Tietz and P. Heitjans, J. Phys. Chem. C, 2016, 120, 8436-8442.

12. Q. Ma, Q. Xu, C.-L. Tsai, F. Tietz and O. Guillon, J. Am. Ceram. Soc., 2016, 99, 410-414.

13. L. Hallopeau, D. Bregiroux, G. Rousse, D. Portehault, P. Stevens, G. Toussaint and C. Laberty-Robert, J. Power Sources, 2018, 378, 48-52.

14. E. Zhao, F. Ma, Y. Jin and K. Kanamura, J. Alloys Compd., 2016, 680, 646-653.

15. K. M. Kim, D. O. Shin and Y.-G. Lee, Electrochim. Acta, 2015, 176, 1364-1373.

16. T. Hupfer, E. C. Bucharsky, K. G. Schell, A. Senyshyn, M. Monchak, M. J. Hoffmann and H. Ehrenberg, Solid State Ionics, 2016, 288, 235-239.

17. H. Aono, E. Sugimoto, Y. Sadaoka, N. Imanaka and G.-y. Adachi, Solid State Ionics, 1991, 47, 257-264.

18. H. S. Jadhav, M.-S. Cho, R. S. Kalubarme, J.-S. Lee, K.-N. Jung, K.-H. Shin and C.-J. Park, J. Power Sources, 2013, 241, 502-508.

19. L. Zhang, L. Cheng, J. Cabana, G. Chen, M. M. Doeff and T. J. Richardson, Solid State Ionics, 2013, 231, 109-115.

20. T. Zhu, Y. Lin, Z. Yang, D. Su, S. Ma, M. Han and F. Chen, J. Power Sources, 2014, 261, 255-263.

21. H. Bai, J. Hu, X. Li, Y. Duan, F. Shao, T. Kozawa, M. Naito and J. Zhang, Ceram. Int., 2018, 44, 6558-6563.

22. C. F. Xing, F. L. Liu, J. X. Bi and H. T. Wu, J. Mater. Sci. Mater. Electron., 2018, 29, 1374613750.

23. J. Liu, T. Liu, Y. Pu, M. Guan, Z. Tang, F. Ding, Z. Xu and Y. Li, RSC Adv., 2017, 7, 4654546552.

24. V. Epp, Q. Ma, E.-M. Hammer, F. Tietz and M. Wilkening, PCCP, 2015, 17, 32115-32121.

25. J. C. Bachman, S. Muy, A. Grimaud, H.-H. Chang, N. Pour, S. F. Lux, O. Paschos, F. Maglia, S. Lupart, P. Lamp, L. Giordano and Y. Shao-Horn, Chem. Rev., 2016, 116, 140-162.

26. M. Kotobuki, B. Kobayashi, M. Koishi, T. Mizushima and N. Kakuta, Mater. Technol., 2014, 29, A93-A97.

27. B. Yang, X. Li, H. Guo, Z. Wang and W. Xiao, J. Alloys Compd., 2015, 643, 181-185.

28. Q. Ma, M. Guin, S. Naqash, C.-L. Tsai, F. Tietz and O. Guillon, Chem. Mater., 2016, 28, 48214828.

29. S. Naqash, Q. L. Ma, F. Tietz and O. Guillon, Solid State Ionics, 2017, 302, 83-91.

30. T. Degen, M. Sadki, E. Bron, U. König and G. Nénert, Powder Diffr., 2014, 29, S13-S18.

31. F. Ma, E. Zhao, S. Zhu, W. Yan, D. Sun, Y. Jin and C. Nan, Solid State Ionics, 2016, 295, 712.

32. B. E. McNealy and J. L. Hertz, Solid State Ionics, 2014, 256, 52-60.

33. D. C. Sinclair, Bol. Soc. Esp. Ceram. Vidrio, 1995, 34, 55-65.

34. M. Kotobuki, M. Koishi and Y. Kato, lonics, 2013, 19, 1945-1948.

35. E. Dashjav, Q. Ma, Q. Xu, C.-L. Tsai, M. Giarola, G. Mariotto and F. Tietz, Solid State Ionics, 2018, 321, 83-90.

36. S. Breuer, D. Prutsch, Q. Ma, V. Epp, F. Preishuber-Pflügl, F. Tietz and M. Wilkening, J. Mater. Chem. A, 2015, 3, 21343-21350.

37. K. Arbi, S. Mandal, J. M. Rojo and J. Sanz, Chem. Mater., 2002, 14, 1091-1097.

38. E. C. Bucharsky, K. G. Schell, A. Hintennach and M. J. Hoffmann, Solid State Ionics, 2015, 274, 77-82.

39. G.-y. Adachi, N. Imanaka and H. Aono, Adv. Mater., 1996, 8, 127-135.

40. Z. Wen, X. Xu and J. Li, J. Electroceram., 2009, 22, 342-345.

41. C.-M. Chang, Y. I. Lee, S.-H. Hong and H.-M. Park, J. Am. Ceram. Soc., 2005, 88, 1803-1807.

42. E. Zhao, F. Ma, Y. Jin and K. Kanamura, J. Alloys Compd., 2016, 680, 646-653.

43. R. Jiménez, A. del Campo, M. L. Calzada, J. Sanz, S. D. Kobylianska, S. O. Solopan and A. G. Belous, J. Electrochem. Soc., 2016, 163, A1653-A1659. 
Table of Contents

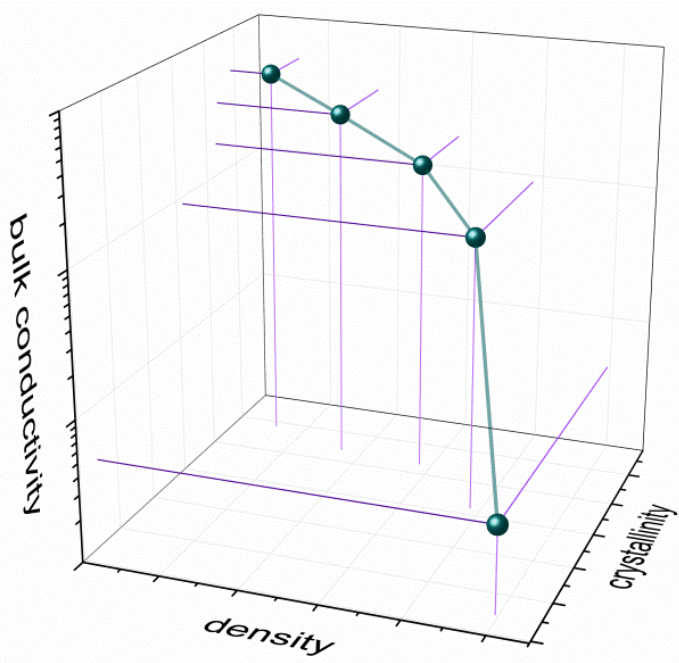

Density, crystallinity, phase purity and compositional homogeneity range are the main factors controlling the bulk ionic conductivity of LATP. 